\title{
Article \\ Cross-Investigation on Copper Nitroprusside: Combining XRD and XAS for In-Depth Structural Insights
}

\author{
Angelo Mullaliu ${ }^{1}\left(\mathbb{D}\right.$, Giuliana Aquilanti ${ }^{2}$, Jasper Rikkert Plaisier ${ }^{2}\left(\mathbb{D}\right.$ and Marco Giorgetti ${ }^{1, *(D)}$ \\ 1 Department of Industrial Chemistry "Toso Montanari", University of Bologna, Viale Risorgimento 4, \\ 40136 Bologna, Italy; angelo.mullaliu@kit.edu \\ 2 Elettra Sincrotrone Trieste S.C.p.A., Strada Statale 14 km 163.5, 34149 Basovizza, Italy; \\ giuliana.aquilanti@elettra.eu (G.A.); jasper.plaisier@elettra.eu (J.R.P.) \\ * Correspondence: marco.giorgetti@unibo.it; Tel.: +39-051-2093-666
}

Citation: Mullaliu, A.; Aquilanti, G.; Plaisier, J.R.; Giorgetti, M. Cross-Investigation on Copper Nitroprusside: Combining XRD and XAS for In-Depth Structural Insights. Condens. Matter 2021, 6, 27. https:// doi.org/10.3390/condmat6030027

\section{Academic Editors:}

Bernardo Barbiellini, Jan Kuriplach and Rolando Saniz

Received: 29 June 2021

Accepted: 23 July 2021

Published: 25 July 2021

Publisher's Note: MDPI stays neutral with regard to jurisdictional claims in published maps and institutional affiliations.

Copyright: (c) 2021 by the authors. Licensee MDPI, Basel, Switzerland. This article is an open access article distributed under the terms and conditions of the Creative Commons Attribution (CC BY) license (https:// creativecommons.org/licenses/by/ $4.0 /)$.

\begin{abstract}
The emerging energy demand and need to develop sustainable energy storage systems have drawn extensive attention to fundamental and applied research. Anion redox processes were proposed in cathodic materials in addition to traditional transition metal redox to boost the specific capacity and the electrochemical performance. Alternatively, copper nitroprusside (CuNP) features an electroactive nitrosyl ligand alongside the two structural metals $(\mathrm{Fe}, \mathrm{Cu})$, representing an alternative to anion redox in layered oxides. Here, a deep structural investigation is carried out on CuNP by complementing the long-range order sensitivity of X-ray diffraction (XRD) and the local atomic probe of X-ray absorption (XAS). Two different CuNP materials are studied, the hydrated and dehydrated forms. A new phase for hydrated CuNP not reported in the literature is solved, and Rietveld refined. The XAS spectra of the two materials at the $\mathrm{Cu}$ and Fe K-edges show a similar yet different atomic environment. The extended XAS spectra (EXAFS) analysis is accomplished by considering threeand four-body terms due to the high collinearity of the atomic chains and gives accurate insight into the first-, second-, and third-shell interatomic distances. Both materials are mounted in Li-ion and $\mathrm{Na}$-ion cells to explore the link between structure and electrochemical performance. As revealed by the charge/discharge cycles, the cyclability in Na-ion cells is negatively affected by interstitial water. The similarity in the local environment and the electrochemical differences suggest a long-range structural dependence on the electrochemical performance.
\end{abstract}

Keywords: prussian blue analogs; batteries; copper; EXAFS; Pawley refinement; Rietveld refinement; multiple scattering; nitroprusside

\section{Introduction}

In this growing age of clean energy demand and efficient use of resources to circumvent the use of traditional fossil fuel technologies, batteries of greater capacity, storage capability, and efficiency are becoming increasingly indispensable [1]. Li-ion batteries (LIB), since their commercialization in 1991 by SONY [2], have outperformed other systems, constituting $63 \%$ of worldwide sales value in portable batteries. There is currently widespread attention being paid to them at both the fundamental and applied levels, as demonstrated by the indispensable use of LIB in electric vehicles nowadays [3]. The reason for this resides in the low reduction potential, as Li has $-3.045 \mathrm{~V}$ vs. SHE (Standard Hydrogen Electrode), which in turn provides Li-based batteries with the highest possible cell potential. Additionally, Li is the third lightest element and has one of the smallest ionic radii of any single charged ion. These factors allow Li-based batteries to have high gravimetric and volumetric capacity and power density $[3,4]$. Concerns regarding the uneven distribution of the Li resources, combined with its relatively low abundance, have led to the use of other alkali metal ions with suitable reduction potential. As a result, sodium (SIB) and potassium ion (KIB) battery technology has recently been paid increasing attention inside the scientific community, representing a valid alternative to Li-ions, with such ions being 
abundant with a reduction potential of $-2.924 \mathrm{~V}$ vs. SHE for potassium and $-2.711 \mathrm{~V}$ vs. SHE for sodium.

The traditional cathode materials used as a cathode for LIB and SIB were transition metal oxides, where the metal oxo-reduction (redox) activity balances the intercalation/release of the $\mathrm{Li}$ or $\mathrm{Na}$ ions during the charge and discharge processes of the battery. To enhance the capacity of cathode materials, additional redox of oxide anions, including the formation of peroxides, $\mathrm{O}^{2-}$ and even molecular oxygen, were proposed [5-7], in addition to the traditional transition metal redox.

Prussian blue analogs (PBA) represent an interesting family of bimetallic cyanides with suitably rigid and open crystal structures for lithium and sodium intercalation reactions [8-10]. The structure of PBAs is generally classified as "soluble" or "insoluble". The "soluble" structure is highly ordered with the metallic atoms in a 1:1 ratio, placed in an octahedral environment, and connected through cyanide ligands. Contrarily, the "insoluble" form is distinguished by the absence of $\left[\mathrm{Fe}(\mathrm{CN})_{6}\right]^{4-}$ units, also referred to as vacancies, and their replacement by water molecules. By replacing a cyanide ligand only with a nitrosyl group, a more flexible structure possessing the same typical PBAs is obtained [11]. The first electrochemical testing of the copper analog against Li indicated a quite interesting capability rate [12], where the nitrosyl ligand could act as an additional redox center $[13,14]$. In this paper, we compare the periodic and the local structure of two copper nitroprusside polymorphs, $\mathrm{Cu}\left[\mathrm{Fe}(\mathrm{CN})_{5} \mathrm{NO}\right](\mathrm{CuNP})$, one hydrated and the other anhydrous, in order to assess the structural/property relationship of the two phases while using both materials in LIB and SIB cells, in terms of cyclability. Interestingly, the local structure around the metals $\mathrm{Cu}$ and Fe is found to be similar in the two phases; thus, the differences found in the cyclability test suggested a long-range structural dependence.

\section{Results}

\subsection{X-ray Powder Diffraction}

By considering the reference structure reported by Gómez et al. [15], a Pawley refinement was performed on the XRD pattern of the hydrated compound by using the Amm2 orthorhombic space group. Figure 1 a shows the best-fit result of the $\mathrm{CuNP} \cdot 2 \mathrm{H}_{2} \mathrm{O}$. The fit appears overall to be good, and the fit goodness parameter is satisfying $\left(R_{w p}=9.063 \%\right)$. However, by taking a closer look at some reflections, it is discernable that the adopted reference model has a higher symmetry than the actual one. Indeed, (113) and (222) reflections presented in the insets of Figure $1 \mathrm{a}$ are not well fitted by using the orthorhombic structure. The signal arising in these regions comes from different contributions that are not taken into consideration by the orthorhombic space group. For this reason, the cell indexing was conducted anew, revealing a better match with a monoclinic symmetry.

Figure $1 b$ displays the Pawley refinement performed with the $P 2 / m$ space group, highlighting the better suitability of the newly considered space group to describe the reflections in the $20.1-20.3^{\circ}$ and $25.5-25.7^{\circ} 2 \theta$ range (cf. insets in Figure 1 ). Hence, the structure found in this work is new and has never been reported before. The fit reported in Figure $1 b$ was carried out by using a generalized $\mu$ strain model, which better delineates the peak shape for different reflections, as reported in the Supplementary Information. After the Pawley refinement was conducted with the $P 2 / m$ space group, the crystal structure was solved using the charge flipping algorithm of GSAS-II. The obtained crystal structure was successively refined through Rietveld refinement, as shown in Figure 2a. At the same time, Table S1 reports the Rietveld refinement results, including the fit goodness $\left(\mathrm{R}_{\mathrm{wp}}=6.397 \%\right)$, the lattice parameters, the microstrain parameters, the atomic parameters, and the relevant bond lengths and angles. $\mathrm{Fe}^{\mathrm{II}}$ - and $\mathrm{Cu}^{\mathrm{II}}$-ions are located in octahedral sites, the Fe surrounded by $5-\mathrm{CN}^{-}$and $1-\mathrm{NO}^{+}$, while the $\mathrm{Cu}$ bonded to $4-\mathrm{NC}^{-}$and $2-\mathrm{OH}_{2}$ molecules (being the oxygen labeled as $\mathrm{O}^{1}$ ). In the coordination sphere of iron, four cyanides (labeled as $-\mathrm{C}^{1} \mathrm{~N}^{1}$ ) act as bridging ligands between the iron and the copper, while the nitrosyl ligand $\left(-\mathrm{N}^{3} \mathrm{O}^{2}\right)$ and the remaining cyanide in the trans position with respect to it $\left(-\mathrm{C}^{2} \mathrm{~N}^{2}\right)$ do not bridge the two metals. Both $\mathrm{Fe}^{\mathrm{II}}$ and $\mathrm{Cu}^{\mathrm{II}}$-ions are placed 
in a distorted octahedral environment. The iron coordination sphere is contracted along the axial direction and filled by four equivalent cyanides $\left(-C^{1} \mathrm{~N}^{1}\right)$ with the $C$-end placed at 2.015(7) $\AA$ from the iron; the additional C-terminal of the other $-\mathrm{C}^{2} \mathrm{~N}^{2}$ is, instead, placed at $1.933(9) \AA$, while the $\mathrm{N}$-atom of the $-\mathrm{N}^{3} \mathrm{O}^{2}$ is at $1.687(9) \AA$. On the other side, the copper coordination is characterized by the four equivalent bridging cyanides $\left(\mathrm{Cu}^{1}\right.$ $\left.\mathrm{N}^{1}=2.029(6) \AA\right)$ and two equivalent water molecules $\left(\mathrm{Cu}^{1}-\mathrm{O}^{1}=2.414(9) \AA\right)$, so that the $\mathrm{Cu}$ coordination sphere can be described as an axial-elongated octahedron. The nitrosyl ligand $\left(-\mathrm{N}^{3} \mathrm{O}^{2}\right)$ and the trans cyanide $\left(-\mathrm{C}^{2} \mathrm{~N}^{2}\right)$ are interchangeable due to the site symmetry (with a site multiplicity of 2) and, therefore, have a fixed occupancy equal to 0.5 . On the contrary, the metals and the remaining cyanides have an occupancy equal to 1.0. Furthermore, the $\mathrm{Fe}^{1}-\mathrm{N}^{3}-\mathrm{O}^{2}$ three-body fragment is characterized by $\mathrm{Fe}^{1}-\mathrm{N}^{3}=1.687(9) \AA$ and $\mathrm{N}^{3}-\mathrm{O}^{2}=$ $1.195(13) \AA$ A bond lengths and by a $172(7)^{\circ}$ bond angle. This may indicate a partial reduced $-\mathrm{NO}^{(+1-\delta)}$ ligand, enforced by the high $\mathrm{U}_{\text {iso }}$ parameter $(0.190(25))$ for the oxygen atom $\left(\mathrm{O}^{2}\right)$, likely due to the partial $s p^{2}$ character of the nitrogen atom and, hence, the spatial delocalization of the oxygen atom.
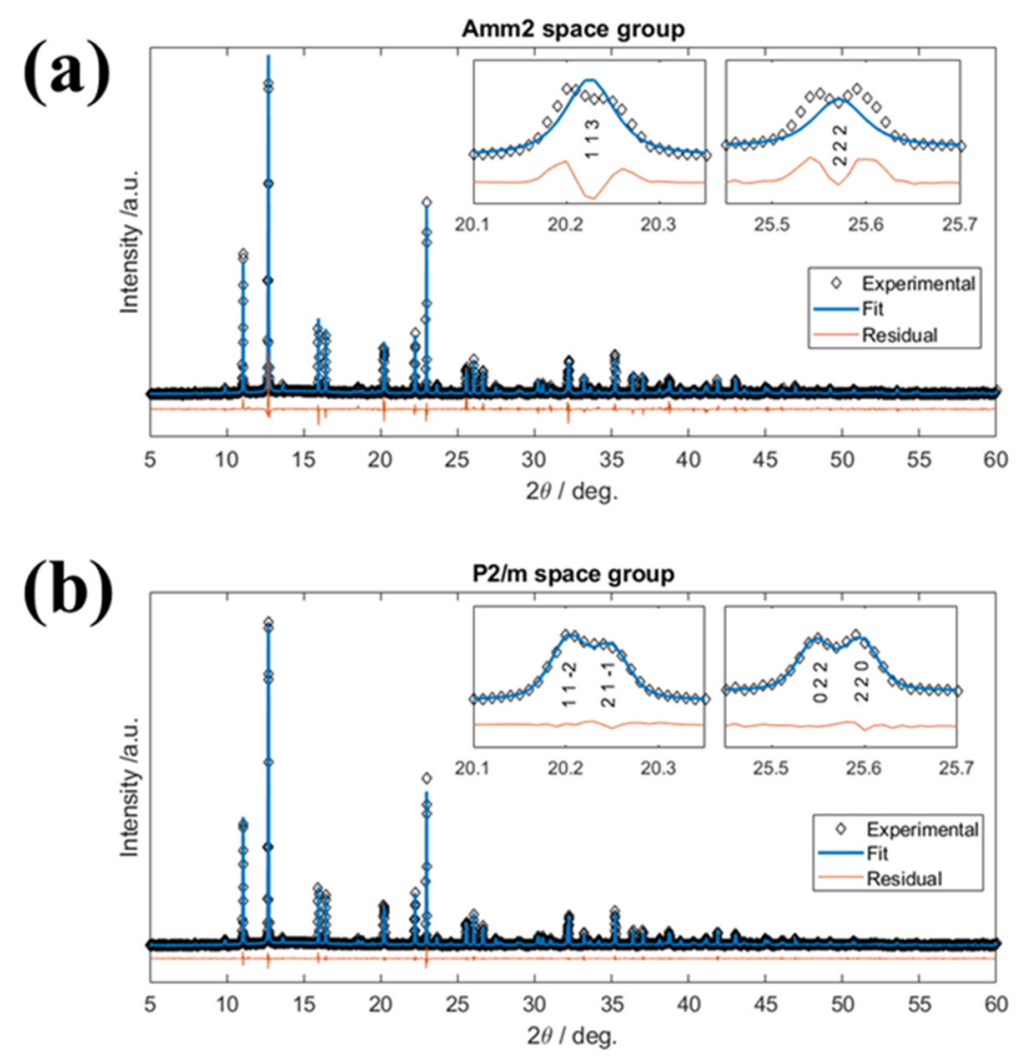

Figure 1. Pawley refinement on the hydrated structure with (a) Amm2 space group and (b) $P 2 / m$ space group. In the case of the monoclinic space group, a generalized $\mu$ strain model was adopted.

Analogous data analysis was carried out for the anhydrous CuNP structure. First, the cell was indexed, then Pawley refinement was carried out on the indexed cell, followed by charge flipping structure solution, and Rietveld refinement was finally done. The cell was successfully indexed in the tetragonal $14 \mathrm{~mm}$ space group, and the solved structure matched well with the reported one [15]. Figure S3 reports the best fit of the Pawley refinement conducted by using a generalized $\mu$ strain model, which better describes the peak shape of different reflections (cf. SI). The fit goodness associated with the Pawley refinement on the anhydrous CuNP structure is satisfying, with an $\mathrm{R}_{\mathrm{wp}}$ factor equal to $5.922 \%$. 

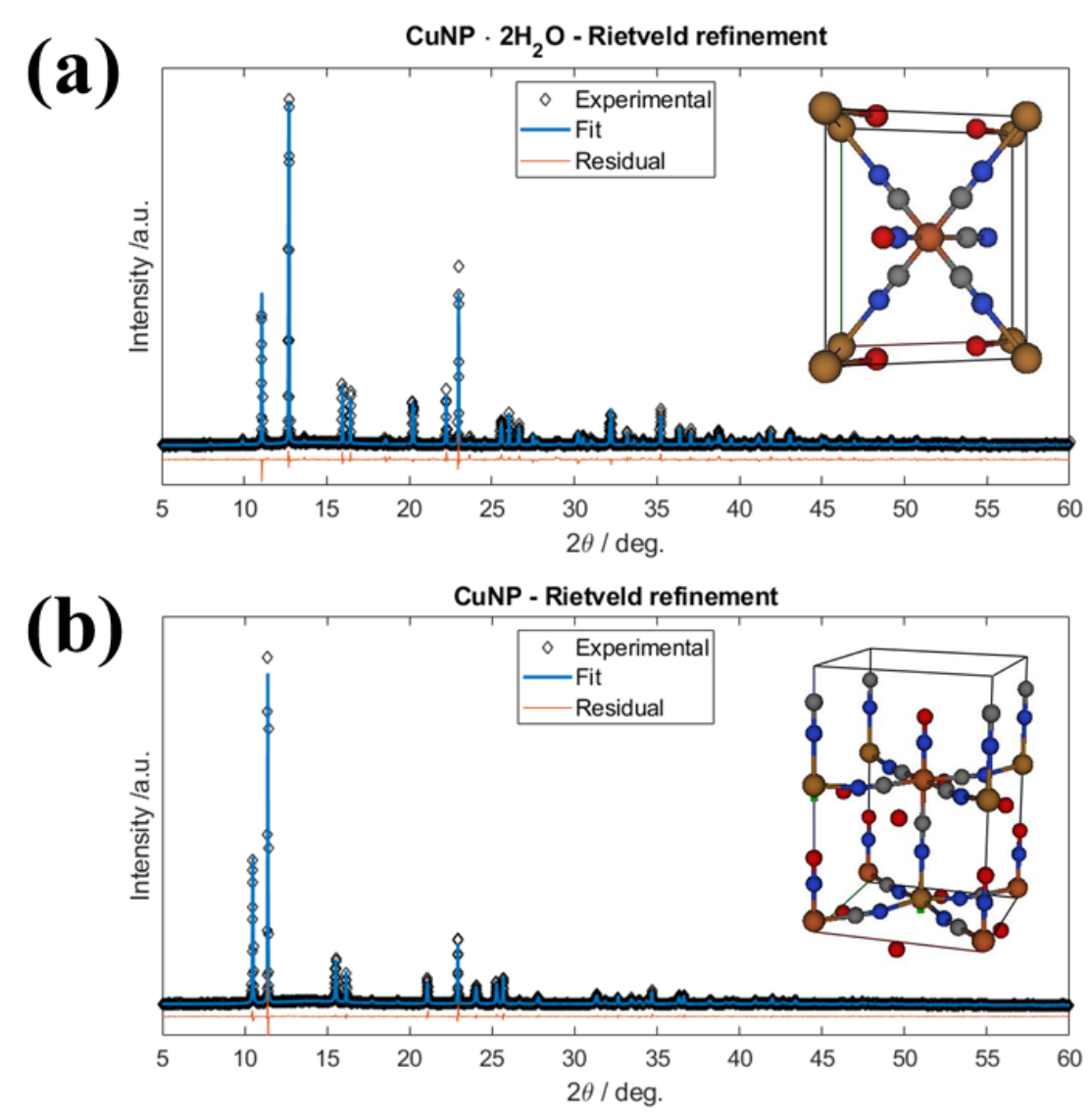

Figure 2. Rietveld refinement and resolved structure for (a) hydrated $\mathrm{CuNP} \cdot 2 \mathrm{H}_{2} \mathrm{O}$ and (b) anhydrous CuNP. The sketch in each panel displayed the structure where the Fe and $\mathrm{Cu}$ atoms (in brown) are linked together via CN ligand (gray and blue, respectively). The NO ligand (blue and red, respectively) is coordinated by the $\mathrm{Cu}$.

The structure was solved by charge flipping and further refined through Rietveld refinement to fine-tune the atomic parameters. Figure $2 b$ presents the visual result of the final refinement, while Table S2 reports the Rietveld refinement results, including the fit goodness $\left(R_{\mathrm{wp}}=6.099 \%\right)$, the lattice parameters, the microstrain parameters, the atomic parameters, and relevant bond lengths and angles. From both Figure $2 \mathrm{~b}$ and Table S2, it is discernable that $\mathrm{Fe}$ and $\mathrm{Cu}$ atoms have different coordination geometries: while six ligands octahedrally surround the Fe species, the $\mathrm{Cu}$ ions are at the basis of a distorted squarebased pyramid and bonded to five ligands. The coordination sphere of Fe is made of four equivalent (equatorial) cyanides, labeled as $-C^{1} \mathrm{~N}^{1}$, one additional cyanide ligand, $-\mathrm{C}^{2} \mathrm{~N}^{2}$, and the nitrosyl ligand, $-\mathrm{N}^{3} \mathrm{O}^{2}$. All cyanides bridge the two metals, $\mathrm{Fe}$ and $\mathrm{Cu}$, while the nitrosyl ligand is non-bridging, with the corresponding oxygen $\left(\mathrm{O}^{2}\right)$ being approximately $3 \AA$ from the $\mathrm{Cu}$ atom. The cyanide ligands, $-\mathrm{C}^{1} \mathrm{~N}^{1}$ and $-\mathrm{C}^{2} \mathrm{~N}^{2}$, are almost equidistant from the Fe center, being the $\mathrm{Fe}-\mathrm{C}$ bond lengths equal to 1.950(5) and 1.948(8) $\AA$, respectively, while the linear $\mathrm{Fe}^{1}-\mathrm{N}^{3}-\mathrm{O}^{2}$ fragment features $\mathrm{Fe}^{1}-\mathrm{N}^{3}=1.602(22) \AA$ and $\mathrm{N}^{3}-\mathrm{O}^{2}=1.129(8) \AA$ bond lengths, in line with the $s p$ hybridization of the nitrogen $\mathrm{N}^{3}$ atom and a formal $(+1)$ oxidation state of the nitrosyl ligand. Moreover, the $\mathrm{Cu}$ coordination sphere is constituted by the bridging cyanides, i.e., the four basal $-\mathrm{N}^{1} \mathrm{C}^{1}$ and the apical $-\mathrm{N}^{2} \mathrm{C}^{2}$, which are placed almost symmetrically around the $\mathrm{Cu}$ ions $\left(\mathrm{Cu}^{1}-\mathrm{N}^{1}=2.074(4) \AA\right.$ and $\left.\mathrm{Cu}^{1}-\mathrm{N}^{2}=2.124(16) \AA\right)$. As the apical $\mathrm{Cu}-\mathrm{N}$ is $2.4 \%$ longer than the basal bond lengths, the $\mathrm{Cu}$ coordination sphere can be considered slightly elongated along the axial $c$ direction. Some residual water, whose oxygen atom is labeled as $\mathrm{O}^{1}$, is still present in a highly delocalized site $\left(\mathrm{U}_{\text {iso }}=0.18(15)\right)$. According to the refined occupancy and the respective site multiplicity, the residual water amounts to $\sim 0.08$ equivalents per CuNP unit formula. 


\subsection{X-ray Absorption Spectroscopy}

The strong selectivity of the XAS technique for the atomic species allows monitoring the local structure of both $\mathrm{Cu}$ and $\mathrm{Fe}$ in the studied samples, thus revealing complementary structural information with respect to the longer order provided by the XRPD. The $\mathrm{Cu}$ and Fe K-edges XANES spectra of Figure S6 relative to the hydrated and the anhydrous copper nitroprusside are similar, suggesting a similar local structure in both phases, as reported previously [16]. More quantitative local structural information can be gained by analyzing the extended portion of the XAS spectra. Materials based on metal hexacyanoferrates XAS spectra are characterized by a strong multiple scattering (MS) signal at the metal $\mathrm{K}$-edges due to the high degeneracy of the linear atomic chains with angles close to planar, which involves high atomic scatterers. This fact, known for a couple of decades [17], has been reported and summarized more recently [18]. Briefly, (i) the MS signals arise from both three- and four-body contributions, and the full EXAFS spectrum can be interpreted with a few MS paths only, (ii) the strong MS signal extends up to more than $5 \AA$ in the atoms probed by the XAS technique, which is unusual in EXAFS spectroscopy, (iii) the analysis would imply the multiple edge refinement which allows us not only to constrain common structural variables of the two metal edges but also to account for the oscillation of the strong MS contributions at the Fe K-edge that may overlay the Cu K-edge, overall enhancing the fitting reliability. Figure 3 displays the comparison of the experimental and theoretical $\mathrm{k}^{2}$-EXAFS signals at Fe (Panel a) and Cu K-edges (Panel b) for both powders and their relative FT plots (Panels c, d), whereas Table 1 reports the best fit results in terms of fitted and released structural and non-structural parameters. The theoretical signals of Figure 3 match well within the experimental curves, signifying the accuracy of the present data analysis. It is also relevant to underline the large contribution of the MS signals in the FT plots, where the third peaks in both Fe and $\mathrm{Cu}$ K-edge correspond to the - $\mathrm{Fe}-\mathrm{C}-\mathrm{N}-\mathrm{Cu}$ chain (and therefore to the four body MS term), which is enhanced due to the strong MS contribution.
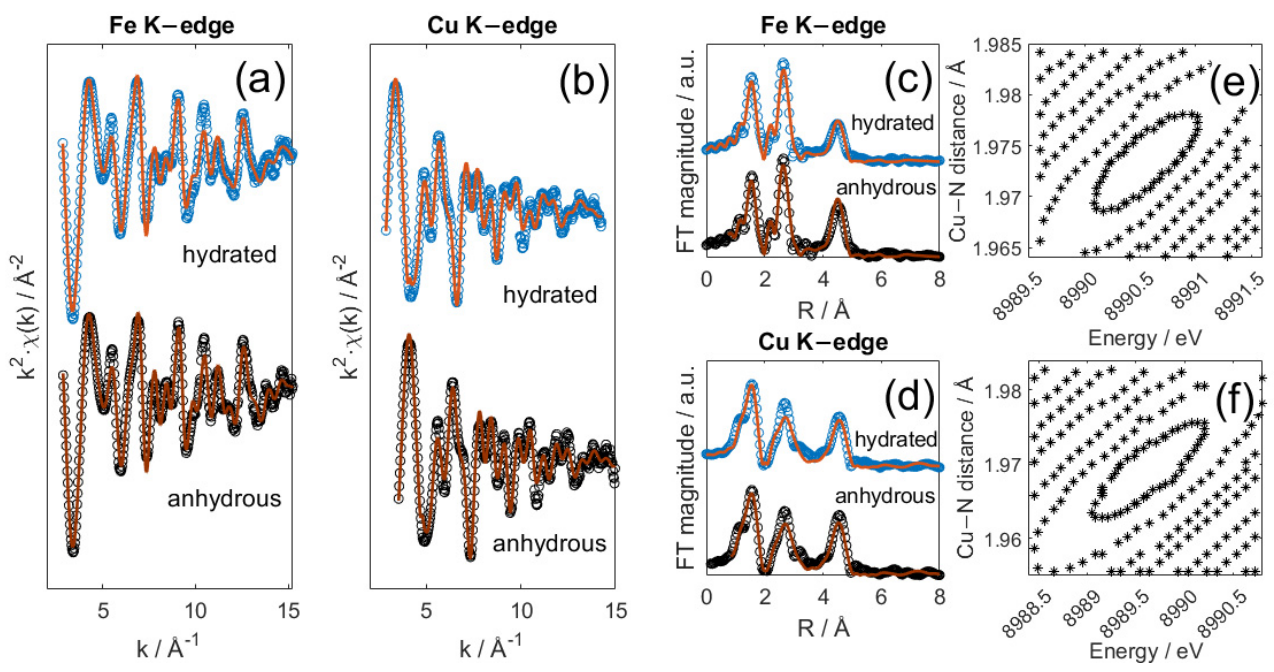

Figure 3. EXAFS best fit result, in terms of $(\mathbf{a}, \mathbf{b}) \mathrm{k}^{2}$-extracted EXAFS and relative (c,d) FTs, for hydrated and anhydrous $\mathrm{CuNP}$, at both $\mathrm{Fe}$ and $\mathrm{Cu}$ K-edges. (e,f) Contour plots of the highly correlated variables $\mathrm{Cu}-\mathrm{N}$ first-shell bond distance and $\mathrm{E}_{0}$ values.

The Fe-C bond lengths match, within their accuracy, in the two samples, giving a value of 1.916(3) and 1.916(4) $\AA$, respectively. The same holds true for the $\mathrm{C} \equiv \mathrm{N}$ and $\mathrm{Cu}-\mathrm{N}$ interactions, thus confirming a very close structure for hydrated and anhydrous material. A statistical analysis has been computed on the bond lengths quotation. Examples are displayed in Figure 3 panels e and $\mathrm{f}$ for the highly correlated variables first shell bond distance and $\mathrm{E}_{0}$ values, providing a clear ground of the parameter's reliability. More contour plots are available in Figure S7. From the table, it is also seen that the -Cu-N-C-Fe- 
linear chains in both materials similarly vibrate around their equilibrium position as seen from their EXAFS bond variances relative to the $\mathrm{Fe}-\mathrm{C}, \mathrm{C} \equiv \mathrm{N}$, and $\mathrm{Cu}-\mathrm{N}$ pair interactions and of the angular deviation. A consistent difference regards the replacement of the nitrogen with oxygen (from water) in the coordination sphere of $\mathrm{Cu}$ for the hydrated sample, which lies at $2.48 \AA$. That oxygen is slightly bounded to the $\mathrm{Cu}$ as the corresponding bond variance is extremely high with respect to any other first shell's contribution.

Table 1. EXAFS fitting results.

\begin{tabular}{|c|c|c|}
\hline & Anhydrous CuNP & Hydrated CuNP \\
\hline $\mathrm{Fe}-\mathrm{C}(\mathrm{x} 5) / \AA$ & $1.916(3)$ & $1.913(4)$ \\
\hline$\sigma^{2} \mathrm{Fe}-\mathrm{C} / \AA^{2}$ & $0.0021(8)$ & $0.0023(7)$ \\
\hline $\mathrm{C} \equiv \mathrm{N}(\mathrm{x} 5) / \AA$ & $1.154(3)$ & $1.150(5)$ \\
\hline$\sigma^{2} \mathrm{C} \equiv \mathrm{N} / \AA^{2}$ & $0.012(1)$ & $0.008(1)$ \\
\hline $\mathrm{Cu}-\mathrm{N}(\mathrm{x} 4) / \AA$ & $1.973(5)$ & $1.969(7)$ \\
\hline$\sigma^{2} \mathrm{Cu}-\mathrm{N} / \AA^{2}$ & $0.0038(6)$ & $0.004(1)$ \\
\hline $\mathrm{Cu}-\mathrm{N} / \mathrm{O}(\mathrm{x} 1 / \mathrm{x} 2) / \AA$ & $2.13(2)$ & $2.48(2) *$ \\
\hline$\sigma^{2} \mathrm{Cu}-\mathrm{N}(\mathrm{O}) / \AA^{2}$ & $0.018(3)$ & $0.034(3)$ \\
\hline $\mathrm{Fe}-\mathrm{N}(\mathrm{x} 1) / \AA$ & $1.68^{* *}$ & $1.68^{* *}$ \\
\hline$\sigma^{2} \mathrm{Fe}-\mathrm{N} / \AA^{2}$ & $0.0024 * *$ & $0.0015^{* *}$ \\
\hline $\mathrm{N}-\mathrm{O} / \AA$ & $1.12 * *$ & $1.11^{* *}$ \\
\hline$\sigma^{2} \mathrm{~N}-\mathrm{O} / \AA^{2}$ & $0.001^{* *}$ & $0.001^{* *}$ \\
\hline$\theta$ Fe-C-N/deg & 180 FIX & 180 FIX \\
\hline$\sigma^{2}$ Fe-C-N/deg ${ }^{2}$ & $4(3)$ & $4(3)$ \\
\hline$\sigma^{2} \mathrm{Cu}-\mathrm{N}-\mathrm{C} / \mathrm{deg}^{2}$ & $9(6)$ & $9(4)$ \\
\hline$\sigma^{2} \mathrm{Fe}-\mathrm{N}-\mathrm{O} / \mathrm{deg}^{2}$ & $63(40)$ & $59(40)$ \\
\hline$\theta$ Fe-N-O/deg & 180 FIX & 180 FIX \\
\hline $\mathrm{E}_{0} \mathrm{Fe}$ & $7119.6(5)$ & 7119.1(4) \\
\hline $\mathrm{E}_{0} \mathrm{Cu}$ & $8992.0(6)$ & $8989.6(6)$ \\
\hline $\mathrm{S}_{0}^{2} \mathrm{Fe}$ & $0.77(6)$ & $0.75(5)$ \\
\hline $\mathrm{S}_{0}^{2} \mathrm{Cu}$ & $0.89(5)$ & $0.89(5)$ \\
\hline$\chi^{2}$-like residual $/\left(10^{-6}\right)$ & 1.66 & 1.29 \\
\hline
\end{tabular}

It is also worth noting that, to limit the number of parameters used in the minimization, the Fe-N-O angle was set to be $180^{\circ}$, regardless of whether it is actually less than planar.

\subsection{Electrochemical Testing}

The charge/discharge $(C / D)$ cycles for the hydrated and dehydrated forms of CuNP are presented in Figure 4. The materials were formulated in the same manner and mounted in both Li-ion and Na-ion cells to assess their electrochemical behavior. By comparing $\mathrm{CuNP}$ and hydrated CuNP with Li (cf. panels a and b), the electrochemical performance is comparable: the specific capacity in charge decreases during the first cycles, while the coulombic efficiency increases. After 50 cycles, the reversible capacity is about $40 \mathrm{mAh} \mathrm{g}^{-1}$ in both cases. While the electrochemical behavior in Li-ion cells is similar, the performance in Na-ion cells is better for the dehydrated form. Although the performance vs. Na is inferior to the one in Li-ion cells, the hydrated form of CuNP does not reversibly insert and extract Na-ions, as displayed in Panel d. Instead, the anhydrous form is able to accommodate a low amount of Na-ions: indeed, a reversible and stable capacity of $20 \mathrm{mAh} \mathrm{g}^{-1}$ is reached after 30-40 cycles. However, the obtained reversible capacity vs. $\mathrm{Na}$ is only half compared to the Li-ion cells. 

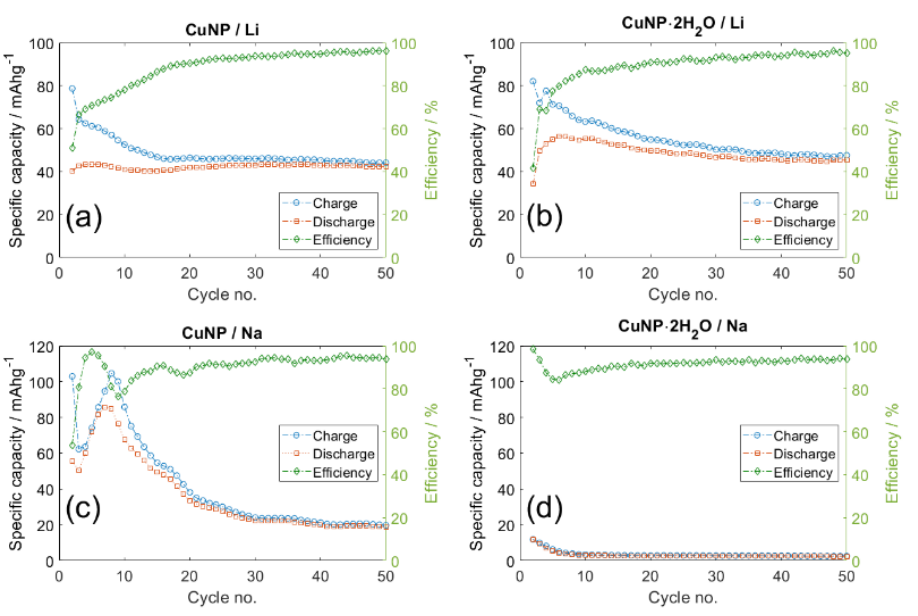

Figure 4. Electrochemical charge/discharge (C/D) cycles for (a,c) anhydrous CuNP and (b,d) hydrated CuNP. $2 \mathrm{H}_{2} \mathrm{O}$. The electrochemical performance has been assessed both in $(\mathbf{a}, \mathbf{b}) \mathrm{Li}$-ion $(\mathbf{c}, \mathbf{d})$ and Na-ion cells.

A plausible reason for this behavior could be that interstitial water in $\mathrm{CuNP} \cdot 2 \mathrm{H}_{2} \mathrm{O}$ may compete with Na-ion and hinder the ion intercalation process, hence the specific capacity in discharge. Instead, the smaller ionic radius of $\mathrm{Li}(90 \mathrm{pm}$ vs. $116 \mathrm{pm}$ for $\mathrm{Na}+$ ) might allow its insertion in smaller cavities different from the water sites.

\section{Discussion}

In this work, structural insight into the CuNP was achieved by complementing the long-range order probed by XRD and the local structural environment retrieved by EXAFS. The structural features of CuNP were thoroughly analyzed and related to the electrochemical performance in Li-ion and $\mathrm{Na}$-ion cells.

A new phase for CuNP was found. According to a comprehensive review on transition metal nitroprussides [11], three different phases were retrieved for CuNP, i.e., two orthorhombic phases (Pnma and Amma) and a tetragonal one (I4mm). While the Pnma phase is obtained through a slow-diffusion method, the other two structures are reported for precipitation-based methods, analogously as in this work. The orthorhombic phase is commonly attributed to the hydrated CuNP compound and the tetragonal to the dehydrated form. However, we have demonstrated that the orthorhombic Anma space group has a symmetry too high to describe the reflections of the hydrated form correctly. As a matter of fact, the structure was solved, and a monoclinic $(P 2 / m)$ structural model better fits the experimental pattern.

Due to the high sensitivity of EXAFS to the local environment of the photoabsorber, the first-, second-, and third-shell distances retrieved by this analysis have much higher accuracy than the respective bond lengths obtained by XRD analysis. This is particularly true for the $\mathrm{Cu}-\mathrm{N}$ equatorial pair in the dehydrated compound, where the discrepancy between EXAFS and XRD is relatively high $(\Delta=5 \%)$ compared to other pairs.

Moreover, the slight interatomic discrepancies in other cases are likely due to the different adopted probes. While XRD stems from the diffraction of photons by electron clouds, the multiple scattering of the ejected photoelectron depends on the potential described by the surrounding atoms and centered on the atom itself. Thus, the interatomic distances might slightly differ in the two characterization methods.

Given the novelty concerning the new phase identification, we carried out electrochemical tests using both CuNP forms to relate the structural-electrochemical properties. The electrochemical performance against $\mathrm{Li}$ is similar for both hydrated and dehydrated CuNP materials, while the performance in Na-ion organic electrolyte is lower for the hydrated form. Given that the local surrounding area of $\mathrm{Cu}$ and Fe sites is almost equivalent in both samples, as shown in the XANES spectra (cf. SI), the reason for the different performance 
might lie in the long-range order. Moreover, the interstitial water in $\mathrm{CuNP} \cdot 2 \mathrm{H}_{2} \mathrm{O}$ may compete with Na-ions and hinder the ion intercalation process, while the Li-ion shuttling might not be affected due to its much lower ionic radius and the possibility to be inserted in smaller cavities $\left(r_{\mathrm{Li}^{+}}=0.77 \cdot r_{\mathrm{Na}^{+}}\right)$. Although the electrochemical performance of CuNP does not compete with other candidates for Li-ion or Na-ion batteries, this work contributes to the overall scientific knowledge on the PBA materials and their possible use as host materials in energy storage applications.

\section{Materials and Methods}

The synthesis of copper nitroprusside was partially based on a co-precipitation method reported in the literature $[12,13]$. Briefly, the co-precipitation occurred from $20 \mathrm{mM}$ solutions of $\mathrm{CuSO}_{4} \cdot 5 \mathrm{H}_{2} \mathrm{O}$ and $\mathrm{Na}_{2}\left[\mathrm{Fe}(\mathrm{CN})_{5}(\mathrm{NO})\right] \cdot 2 \mathrm{H}_{2} \mathrm{O}$, used as purchased by Sigma Aldrich. The simultaneous addition took place either at $40{ }^{\circ} \mathrm{C}$ (anhydrous sample) or $0{ }^{\circ} \mathrm{C}$ (hydrated sample) under constant stirring. The suspension was aged for two days, and the precipitate was collected by centrifugation. After that, the product was placed either directly in a desiccator (hydrated sample) or vacuum-dried at $60{ }^{\circ} \mathrm{C}$ overnight (anhydrous sample).

X-ray diffraction (XRD) patterns were recorded at Elettra-Sincrotrone Trieste (Italy) at the MCX beamline [19] using a monochromatic beam of $1.033 \AA$. The storage ring operated at $2.0 \mathrm{GeV}$ in top-up mode with a typical current of $310 \mathrm{~mA}$. Data were collected in capillary mode consecutively from $10^{\circ}$ to $70^{\circ} 2 \theta$-range with a $0.01^{\circ}$ step and $0.5 \mathrm{~s} /$ point acquisition time. The XRD data analysis was performed using GSAS-II software [20], assuming as structural models the ones reported by Gómez et al. [15]. Instrumental parameters were retrieved from the XRD pattern of a silicon standard powder. Hence, instrumental broadening parameters, i.e., U, V, W, X and Y, were kept fixed during the successive XRD sample refinement. Peak shape was refined by optimizing the microstrain broadening parameter due to the sample only. Cell indexing was first conducted on the XRD patterns to determine the most appropriate space group. The refinement for the hydrated structure was performed in the $5-62.1938^{\circ} 2 \theta$-range, while the $5-62.2076^{\circ}$ range was used for the anhydrous compound $\left(\mathrm{d}_{\text {min }} \sim 1.01 \AA\right.$ ). Pawley refinement was achieved by considering the previously indexed cell and by refining a chebyschev background function, the unit cell parameters, and the microstrain ( $\mu$ strain) in this order. Either an isotropic or a generalized ustrain model was used to model the peak shape and the results deriving from both models are reported in the Supplementary Information. After the Pawley refinement, charge flipping was carried out to solve the structure from powder diffraction data. For the hydrated structure, the peak cut-off was fixed to $10 \%$, the map grid step to 0.1 , and the lower threshold and upper limit for charge flipping to 0.1 and 18, respectively. For the anhydrous structure, the peak cut-off was fixed to $10 \%$, the map grid step to 0.15 , the lower threshold and upper limit for charge flipping to 0.2 and 20, respectively. After solving the structure, Rietveld refinement was carried out by refining the scale factor, the chebyschev background function, the unit cell parameters, the $\mu$ strain, and the atomic parameters in this order. Further details on the charge flipping algorithm may be found in reference [21].

XAS experiments were performed at Elettra-Sincrotrone Trieste (Italy), at the XAFS beamline [22]. The storage ring operated at $2.0 \mathrm{GeV}$ in top-up mode with a typical current of $310 \mathrm{~mA}$. XAS data were recorded at Fe and $\mathrm{Cu}$ K-edges by using ionization chambers filled with a mixture of $\mathrm{Ar}, \mathrm{N}_{2}$, and $\mathrm{He}$, in transmission mode. The energy was calibrated using internal references of iron and copper foil (the first inflection point of the XAS spectra were set to 7112 and $8979 \mathrm{eV}$, respectively, for iron and copper. Spectra at Fe and $\mathrm{Cu}$ K-edges were collected with a constant k-step of $0.03 \AA^{-1}$ with $2 \mathrm{~s} /$ point acquisition time. Data were collected from 6950 to $8050 \mathrm{eV}$ for the Fe K-edges and from 8760 to $9850 \mathrm{eV}$ for the $\mathrm{Cu}$ K-edges. The energy of the synchrotron beam was selected by using a fixed exit monochromator equipped with a pair of $\mathrm{Si}(111)$ crystals. Harmonics rejection was performed by using the cut-off of the reflectivity of the platinum mirror placed at $3 \mathrm{mrad}$ with respect to the beam upstream ( $\mathrm{Cu} \mathrm{K-edge)} \mathrm{or} \mathrm{by} \mathrm{detuning} \mathrm{the} \mathrm{second} \mathrm{crystal} \mathrm{of} \mathrm{the}$ monochromator by $30 \%$ of the maximum (Fe K-edge). 
The EXAFS analysis was performed using the GNXAS package [23,24], which uses the multiple scattering (MS) theory. The method is based on the decomposition of the EXAFS signals into a sum of several n-body terms. The theoretical signal is calculated ab-initio and contains the relevant two-body $\gamma^{(2)}$, three-body $\gamma^{(3)}$, and four-body $\gamma^{(4)}$ MS terms [17]. The two-body terms are associated with pairs of atoms, probing their distances and associated bond variances. The three-body terms are associated with triplets of atoms and probe angles, bond-bond, and bond-angle correlations. The four-body terms are associated with chains of four atoms, and probe distances and angles in-between, and bond-bond and bond-angle correlations. Because of the linearity of the Fe-C-N-Cu chains, all the angles were set to $180^{\circ}$ (this is also true for the Fe-N-O angle), thus reducing the number of parameters, by symmetry, necessary for the description of the three-body and the fourbody terms. Data analysis was performed by minimizing a $\chi^{2}$-like residual function that compares the theoretical (model) signal, $\mu_{\bmod }(\mathrm{E})$, to the experimental one, $\mu_{\exp }(\mathrm{E})$. The phase shifts for the photoabsorber and backscatterer atoms were calculated, starting from the structure reported by Reguera et al. [15], according to the muffin-tin approximation and allowing $10 \%$ overlap between the muffin-tin spheres. The Hedin-Lundqvist complex potential [25] was used for the exchange-correlation potential of the excited state. The core-hole lifetime, $\Gamma_{\mathrm{c}}$, was fixed to the tabulated value [26] and was included in the phase shift calculation. The experimental resolution used in the fitting analysis was around $1 \mathrm{eV}$, in agreement with the stated value for the beamline used.

Suitable electrodes for electrochemical tests were obtained by thoroughly mixing the pure active material (70\%), 10\% carbon black (CB), and 10\% vapor grown carbon fibers-high density (VGCF-H) in an agate mortar; $10 \%$ Teflon (PTFE) was finally added and mixing continued until a homogenous paste was obtained. Disks were cut from the flattened paste using a puncher with an inner diameter of $8 \mathrm{~mm}$. The mass loading of such disks was $2-4 \mathrm{mg} \mathrm{cm}^{-2}$ of active material. Lithium or sodium metal foil was adopted as the negative electrode, $1 \mathrm{M} \mathrm{LiPF}_{6}$ in ethylene carbonate: propylene carbonate: 3 dimethyl carbonate volumetric mixture (EC:PC:3DMC) without additives was used as the electrolyte in Li-ion cells. $1 \mathrm{M} \mathrm{NaPF}_{6}$ in $\mathrm{EC}: \mathrm{DMC}$ without additives served as the electrolyte solution in Na-ion cells. The positive electrode (hydrated or dehydrated CuNP), a Whatman separator soaked in the electrolyte, and the negative electrode were stacked and assembled in 2036 stainless steel coin cells under an inert atmosphere in an Ar-filled glove box. Galvanostatic cycling with potential limitation (GCPL) was conducted in the $1.5<\mathrm{E}<4.0 \mathrm{~V}$ window for Li-ion cells and in the 1.8-4.0 V range for Na-ion cells. Cycling occurred at a C/5 current rate, where $1 \mathrm{C}=114 \mathrm{mAh} \mathrm{g}^{-1}$.

Supplementary Materials: The following are available online at https:/ / www.mdpi.com/article/ 10.3390 / condmat6030027/s1, Figure S1: Pawley refinement on the hydrated structure with P2/m space group. Figure S2: Detail of the Pawley refinement on the hydrated structure with P2/m space group. Figure S3: Pawley refinement on the anhydrous structure with $14 \mathrm{~mm}$ space group and a generalized $\mu$ strain model. Figure S4: Pawley refinement on the anhydrous structure with $14 \mathrm{~mm}$ space group. Figure S5: Detail of the Pawley refinement on the anhydrous structure with I4mm space group. Figure S6: Comparison of the anhydrous and the hydrated structures of copper nitroprusside powders. Figure S7: Examples of the two dimensional section of the parameter space (contour plots) for anhydrous and hydrated copper nitroprusside. Figure S8: Voltage profile of CuNP against Li. Figure S9: Voltage profile of CuNP against Na. Figure S10: Voltage profile of CuNP $2 \mathrm{H}_{2} \mathrm{O}$ against Li. Figure S11: Voltage profile of CuNP $2 \mathrm{H}_{2} \mathrm{O}$ against Na. Table S1: Results of the Rietveld refinement on the hydrated structure. Table S2: Results of the Rietveld refinement on the anhydrous structure.

Author Contributions: M.G. and A.M. conceptualization and methodology of the research project.; investigation and experiments M.G., A.M., G.A., J.R.P.; data analysis and interpretation, A.M. and M.G.; writing-original draft preparation, A.M. and M.G.; writing-review and editing, M.G., A.M., G.A., J.R.P.; All authors have read and agreed to the published version of the manuscript.

Funding: Measurements at ELETTRA were funded by the project number 20180220 (M. Giorgetti as PI) and by in-house research. This research was funded by the University of Bologna, RFO funding. 
Institutional Review Board Statement: Not applicable.

Informed Consent Statement: Not applicable.

Data Availability Statement: The datasets generated and analyzed during the current study are available from the corresponding author on reasonable request.

Conflicts of Interest: The authors declare no conflict of interest.

\section{References}

1. Chu, S.; Cui, Y.; Liu, N. The path towards sustainable energy. Nat. Mater. 2017, 16, 16-22. [CrossRef]

2. Reddy, M.V.; Mauger, A.; Julien, C.M.; Paolella, A.; Zaghib, K. Brief History of Early Lithium-Battery Development. Materials 2020, 13, 1884. [CrossRef] [PubMed]

3. Xu, C.; Dai, Q.; Gaines, L.; Hu, M.; Tukker, A.; Steubing, B. Future material demand for automotive lithium-based batteries. Commun. Mater. 2020, 1, 1-10. [CrossRef]

4. Goodenough, J.B.; Manthiram, A. A perspective on electrical energy storage. MRS Commun. 2014, 4, 135-142. [CrossRef]

5. Oishi, M.; Yamanaka, K.; Watanabe, I.; Shimoda, K.; Matsunaga, T.; Arai, H.; Ukyo, Y.; Uchimoto, Y.; Ogumi, Z.; Ohta, T. Direct observation of reversible oxygen anion redox reaction in Li-rich manganese oxide, $\mathrm{Li}_{2} \mathrm{MnO}_{3}$, studied by soft $\mathrm{X}$-ray absorption spectroscopy. J. Mater. Chem. A 2016, 4, 9293-9302. [CrossRef]

6. Saubanère, M.; McCalla, E.; Tarascon, J.M.; Doublet, M.L. The intriguing question of anionic redox in high-energy density cathodes for Li-ion batteries. Energy Environ. Sci. 2016, 9, 984-991. [CrossRef]

7. House, R.A.; Marie, J.-J.; Pérez-Osorio, M.A.; Rees, G.J.; Boivin, E.; Bruce, P.G. The role of $\mathrm{O}_{2}$ in O-redox cathodes for Li-ion batteries. Nat. Energy 2021, 1-9. [CrossRef]

8. Paolella, A.; Faure, C.; Timoshevskii, V.; Marras, S.; Bertoni, G.; Guerfi, A.; Vijh, A.; Armand, M.; Zaghib, K. A review on hexacyanoferrate-based materials for energy storage and smart windows: Challenges and perspectives. J. Mater. Chem. A 2017, 5, 18919-18932. [CrossRef]

9. Qian, J.; Wu, C.; Cao, Y.; Ma, Z.-F.; Huang, Y.; Ai, X.; Yang, H. Prussian Blue Cathode Materials for Sodium-Ion Batteries and Other Ion Batteries. Adv. Energy Mater. 2018, 8, 1-24. [CrossRef]

10. Choi, D.; Lim, S.; Han, D. Advanced metal-organic frameworks for aqueous sodium-ion rechargeable batteries. J. Energy Chem. 2021, 53, 396-406. [CrossRef]

11. Reguera, L.; Avila, Y.; Reguera, E. Transition metal nitroprussides: Crystal and electronic structure, and related properties. Co-ord. Chem. Rev. 2021, 434, 213764. [CrossRef]

12. Mullaliu, A.; Sougrati, M.-T.; Louvain, N.; Aquilanti, G.; Doublet, M.-L.; Stievano, L.; Giorgetti, M. The electrochemical activity of the nitrosyl ligand in copper nitroprusside: A new possible redox mechanism for lithium battery electrode materials? Electrochim. Acta 2017, 257, 364-371. [CrossRef]

13. Mullaliu, A.; Aquilanti, G.; Stievano, L.; Conti, P.; Plaisier, J.; Cristol, S.; Giorgetti, M. Beyond the Oxygen Redox Strategy in Designing Cathode Material for Batteries: Dynamics of a Prussian Blue-like Cathode Revealed by Operando X-ray Diffraction and X-ray Absorption Fine Structure and by a Theoretical Approach. J. Phys. Chem. C 2019, 123, 8588-8598. [CrossRef]

14. Mullaliu, A.; Stievano, L.; Aquilanti, G.; Plaisier, J.R.; Cristol, S.; Giorgetti, M. The peculiar redox mechanism of copper nitroprusside disclosed by a multi-technique approach. Radiat. Phys. Chem. 2020, 175, 108336. [CrossRef]

15. Gómez, A.; Rodríguez-Hernández, J.; Reguera, E. Unique coordination in metal nitroprussides: The structure of $\mathrm{Cu}\left[\mathrm{Fe}(\mathrm{CN})_{5} \mathrm{NO}\right] \cdot 2 \mathrm{H}{ }_{2} \mathrm{O}$ and $\mathrm{Cu}\left[\mathrm{Fe}(\mathrm{CN})_{5} \mathrm{NO}\right.$. J. Chem. Crystallogr. 2004, 34, 893-903. [CrossRef]

16. Musella, E.; Mullaliu, A.; Ruf, T.; Huth, P.; Tonelli, D.; Aquilanti, G.; Denecke, R.; Giorgetti, M. Detailing the Self-Discharge of a Cathode Based on a Prussian Blue Analogue. Energies 2020, 13, 4027. [CrossRef]

17. Giorgetti, M.; Berrettoni, M.; Filipponi, A.; Kulesza, P.J.; Marassi, R. Evidence of four-body contributions in the EXAFS spectrum of $\mathrm{Na}_{2} \mathrm{Co}\left[\mathrm{Fe}(\mathrm{CN})_{6}\right]$. Chem. Phys. Lett. 1997, 275, 108-112. [CrossRef]

18. Berrettoni, M.; Mullaliu, A.; Giorgetti, M. Metal Hexacyanoferrate Absorbents for Heavy Metal Removal. In Green Adsorbents to Remove Metals, Dyes and Boron from Polluted Water; Springer: Cham, Switzerland, 2021; pp. 171-194.

19. Rebuffi, L.; Plaisier, J.R.; Abdellatief, M.; Lausi, A.; Scardi, P. MCX: A Synchrotron Radiation Beamline for X-ray Diffraction Line Profile Analysis. Z. Anorg. Und Allg. Chem. 2014, 640, 3100-3106. [CrossRef]

20. Toby, B.; Von Dreele, R.B. GSAS-II: The genesis of a modern open-source all purpose crystallography software package. J. Appl. Crystallogr. 2013, 46, 544-549. [CrossRef]

21. Von Dreele, R. Stochastic and Deterministic Crystal Structure Solution Methods in GSAS-II: Monte Carlo/Simulated Annealing Versus Charge Flipping. Crystals 2017, 7, 264. [CrossRef]

22. Aquilanti, G.; Giorgetti, M.; Dominko, R.; Stievano, L.; Arčon, I.; Novello, N.; Olivi, L. Operando characterization of batteries using X-ray absorption spectroscopy: Advances at the beamline XAFS at synchrotron Elettra. J. Phys. D Appl. Phys. 2017, 50, 074001. [CrossRef]

23. Filipponi, A.; Di Cicco, A. X-ray-absorption spectroscopy and n-body distribution functions in condensed matter. II. Data analysis and applications. Phys. Rev. B 1995, 52, 15135-15149. [CrossRef]

24. Filipponi, A.; Di Cicco, A.; Natoli, C.R. X-ray-absorption spectroscopy and n-body distribution functions in condensed matter. I. Theory. Phys. Rev. B 1995, 52, 15122-15134. [CrossRef] [PubMed] 
25. Hedin, L.; Lundqvist, B.I.; Lundqvist, S. Local exchange-correlation potentials. Solid State Commun. 1971, 9, 537-541. [CrossRef]

26. Krause, M.O.; Oliver, J.H. Natural widths of atomic K and L levels, K $\alpha$ X-ray lines and several K L L Auger lines. J. Phys. Chem. Ref. Data 1979, 8, 329-338. [CrossRef] 